\title{
State and prospects of competition, communications and logistics of agro-food products
}

\author{
Hadis Rakhaev ${ }^{1, *}$, Anzor Gyatov ${ }^{1}$, Zalina Ivanova ${ }^{1}$, Elvira Kokova ${ }^{1}$, and Akhmat Chochaev ${ }^{2}$ \\ ${ }^{1}$ Kabardino-Balkarian State Agricultural University named after V.M. Kokov, Lenin Avenue, 1V, \\ 360030 Nalchik, Russia \\ 2 «Development corporation of the Kabardino-Balkarian Republic», JSC
}

\begin{abstract}
Communication and logistics are one of the most important features of the markets; they permeate and constitute its content. Communication and logistics for commodity producers are also as important attribute as production itself, and sometimes even more. For this reason, commodity producers themselves directly and explicitly, but more often through other institutions (including the government), tend to set up stable exclusive communication systems and logistics. This article analyzes the state of the prospects for the formation of communications and logistics networks for agricultural products. The correlation of existing communications and logistics of agricultural products and other types of products (including finished industrial products of various purposes: from machinery, equipment, chemical products to defense, hydrocarbon, carbon and other raw materials, timber and other goods) is analyzed. The established linkages are revealed. They were quantified, calibrated and classified. The existing principles (comparative and absolute advantages) are reviewed and new principles are formulated (marginal player, marginal linkages), which describe the real situation in the markets of agricultural products more correctly. New criteria for grouping and reformatting existing communication and logistics networks, which make it possible to increase the competitiveness of domestic agricultural products are proposed.
\end{abstract}

\section{Introduction}

An observation of the modern and historical practice of the agriculture development shows one trivial case: it is possible to produce (and producing) a good-quality product in a large volume, but not to transform/turn it into a commodity, i.e. not to sell it and in this way all production costs will be a loss. This experience was typical to many countries, from ancient Greece, Egypt, Babylon, and China to the present day. Most often, the basis of an unfinished metamorphosis, when a product does not turn into a commodity, is seen as the low quality of the product and high competition in markets that the manufactured product could not overcome. Therefore, a pair of relations: price-quality acts as a criterion for

\footnotetext{
* Corresponding author: $\underline{\text { r3bizengin@mail.ru }}$
} 
overcoming the barrier. But actually, it is much more complicated. Soviet and Russian agriculture, as well as the agriculture of many other countries, shows that often the problem lies not in this respect, but in communications and logistics, i.e. in the networks. The logic of the appearance of the indicated and described effect of not passing the expected metamorphosis: product-commodity, for products of domestic agriculture, is that the transformation of a product into a commodity is related not to the consumer qualities of the product, but with logistics, communications, i.e. so that the manufacturer finds its consumer. This situation causes the emergence of intermediaries, like those agents who find their consumer for each producer and their product for each consumer. Thus, the experience indicates that it is not enough to produce a product and to supply it with the necessary qualities and price, so that it becomes a commodity (i.e. sold), it is necessary to create its own consumer for each product or create your own communications and logistics.

However, it is one thing when talking about a single product, single producer and consumer, and even a certain industry, and completely different thing when talking about a branch of the national economy and, moreover, agriculture, which produces tens, hundreds of thousands of items of products that are necessary turn into commodities.

Clearly, it is necessary to proceed from the features of these products when forming a communication and logistics system for agricultural products and raw materials. First thing is that they, as a rule, belong to the so-called perishable products. Therefore, the manufacturer has to sell them as soon as possible. There are two forms of marketing: direct or to the final consumer and processor or to the intermediate consumer. At the same time, the manufacturer faces the issue of cost, i.e. in the first case, he earns more than in the second. That is why the manufacturer seeks to find the final consumer of his products himself. Secondly, many of them cannot be kept in the traditional storage, but require special storage and transportation conditions. Thirdly, they correlate (and even complement) with ecology, physiology, and other traits, i.e. can have a negative impact on the environment (carry environmental harm), as well as on the physiology of people and animals. They can be carriers of diseases, pests, etc. Therefore, special measures are required not only for storage and transportation, but also consumption. There are also other features of these products that distinguish them from products of industry, construction, transport and services. However there are also qualities that set them apart for the so-called better side from their competitors. Primarily, they are as versatile as many raw materials. Secondly, they are universal in consumption (use), i.e. do not need any special knowledge, skills and means. And in this regard, they are kind of primitive. Thirdly, they act as the basis for the biological existence of humans and animals. In addition to the listed features, there are also many properties described in any good merchandise science textbook.

The listed features of agricultural products and raw materials certainly must be reflected in the formation of communications and logistics, which, in our view, was the main mistake of the Soviet (and then repeated and seems to continue also in the Russian) system of communications and logistics of agricultural products and raw materials, but, apparently, they are not decisive in the transformation of a product into a commodity. The analysis revealed several fundamental problems in the existing system. The first problem is the lack of consistency in the formation of communications and logistics of agricultural products and raw materials. The second problem is the lack of consistency in the formation of such a system. The third problem is the lack of a principled approach and mechanism in the formation of communications and logistics networks, the use (and following) of stereotypes and tradition, the absence of heuristic solutions. In this paper we are going to consider on these problems, as well as on how to form effective communication and logistics systems. 


\section{Materials and Methods}

The empirical base of the study is official statistics on the production and foreign trade of agro-food and other products published in statistical collections of the FSSS (Rosstat), as well as the results of research by domestic and foreign authors published in the public press: monographs, articles, educational and other manuals. The theoretical and methodological basis of the research was formed by the works of A. Smith, D. Ricardo, J. St. Mill, A. Marshall, M.I. Tugan-Baranovsky, N.D. Konratyev, V.V. Leontiev, P. Samuelson, B. Olin, M. Porter, P. Lindert and other foreign and domestic academic economists, and the principles, categories and concepts formulated in their works. The basic concepts (category and principle) are the Ricardian principle of comparative advantage, in the interpretation of Olin-Heckscher-Samuelson, which is complemented by communications and networks. According to the above, the principle is formulated as follows: the competitive preference, if other things being equal, has not the product with the lowest cost of production, but the product that can be delivered (provided) to the consumer more quickly. Thus, the competitive advantages (preferences) do not consist in production, but in existing (used) communications and logistics. The theoretical and methodological basis of communications and logistics has been developed in various fields of practice and theory: from natural science, technology to humanitarian disciplines. They also receive significant attention in economic and organizational research. In this regard, the epochal works of A. Bogdanov, L. von Bertalanffy [1, 2, 3] formulating methodological basis, as well as a large number of works by contemporaries that can be identified as theoretical and practical in this area $[4,5,6,7,8,9]$ should be mentioned.

\section{Results and Discussion}

The major features of any market are competition, foreign markets, communications and logistics. Currently, it is very difficult for agricultural producers to enter not only foreign markets, but even domestic ones without their own exclusive communications and logistics. In the USSR exclusive logistics systems were formed for agricultural products on world markets. However, mainly the products of domestic agriculture were sold to the countries of the socialist community, as well as African and Latin American countries. Moreover, the prices for products turned out to be symbolic, since the products for export were sold under certain agreements. As for the food and agricultural markets of developed countries: France, Great Britain and Germany in Europe, the USA and Canada in America, etc., they were essentially closed for our agricultural products $[10,11,12]$. Moreover, we imported large quantities of grain, animal oil, vegetable oil and many food products from the USA, Canada, France and Greece. Large amounts of citrus and tropical crops (bananas, coffee, coconut, etc.) were imported from African and Latin American countries. Large amounts of sugar were imported from Cuba, tea from India, vegetables from Hungary and Bulgaria. This was explained by the fact that we did not have our own communications and our own logistics in the sale of food and agricultural products. At present, when the competition in the world agro-food markets has intensified, it is difficult, or even impossible, to sell one's own agricultural products without appropriate sales channels. As for the implementation into communications and logistics of other countries, which is often carried out for some types of products, it results in losses and is inefficient on its own, since we act mainly as a "guest" and not a "owner" of communications. Therefore, it is not we who dictate the terms, but we but we who are dictated by the conditions for the sale of products. Experience shows that the solution of this fundamental problem is impossible without the support of the government. Moreover, this is a worldwide practice that is used by all developed countries all over the world $[11,13,14,15]$. However, one of the promising directions associated 
with the integration of flows of agricultural products, with flows of arms and other military products, as well as raw materials (gas, oil, coal, etc.) could be used for us. Agricultural products could be implemented into the existing supply chains and communications of the above military and raw materials (not only hydrocarbons, but also other ore and nonmetallic materials). Such a variant is rather cheaper for the Russian government than to form new agricultural logistics and communication chains and corridors. Complex, systemic nature in relation to communications and logistics networks is required.

Thus, the listed problems constitute a complex of conditions hindering the development of agriculture. Therefore, the growth that has been observed in domestic (including in most regions) agriculture in recent years was formed, firstly, by a limited set of industries (mainly grain production, pork production, poultry production, and some other segments), secondly, the price factor was a major factor in its provision (price increases led to an increase in price trajectory in the overall growth trend), thirdly, by means of food embargo measures established and implemented since 2014 by decrees of the President of the Russian Federation and Resolutions of the Government of the Russian Federation [16, 17]. These measures ensured a kind of "greenhouse" development of national agriculture, protecting it from foreign competitors. (During this period, the so-called "national champions" were born as large vertically integrated national agro-food companies: Miratorg Agribusiness Holding, RIF Trade House, Agrocomplex named after N.I. Tkachev, RUSAGRO Group, Krasnodarzernoprodukt Group (KZP), Prioskolie, Stavropolsky broiler LLC, Agrokombinat Yuzhny JSC, Agro-Invest LLC. The latter can be compared with those that existed in the 90s and early 2000s [18]). However, according some experts, the situation in certain sub-sectors and segments will probably change radically with the opening of borders and the liberalization of foreign relations.

Where do the material and analysis result in? Primarily, the development of domestic agriculture requires the formation of efficient communications and logistics networks, i.e. the creation of a network effect in the industry, a specific effect of the presence of networks in the reproductive process of the industry (product, production). By its very nature, the network effect is multiplicative, i.e. defined somewhere (on one link or product) it stimulates activity in other chains and products. Today, it is clear that access to external markets (as well as to domestic markets) is not possible without own (exclusive) communications and logistics [19, 20, 21, 22]. But the establishment of such communications and logistics proves to be very expensive and complex, both because of the high level of competition and, in fact, because of the lack of free markets, and because of our companies' lack of experience in establishing such communications and logistics networks. Of course it is not necessary to give up on this, since the struggle for agro-food markets in the world will only increase and if peculiar «windows of opportunities» appear, it is necessary to be ready to take up the released traffic and post them for own purpose. (Such experience exists. An example is the grain market, in which Russia, since 2014, has become the dominant player and global actor [23, 24, 25]. But it should not be forgotten that Russia has been coming to this role since the second half of the $90 \mathrm{~s}$ and the entire first decade and half of the second 2000s [26, 27]. There is a market opportunity for poultry [28] and pork [29, 30,31], which are still poorly developed by domestic agricultural industry. But we should not forget about the power and greatness of Russia and two or three segments with which we can enter world markets. Resource potential of Russian agriculture allows to create dominance in more than a dozen commodity segments

The experience of the grain industry indicates the costs that had to be incurred to obtain its communications and logistics (traffic) only in the grain market. But there is a less expensive and more efficient way to build own communications and logistics networks in the area of agro-food. It refers to the entry (integration, cooperation) of the agro-food sector with the defense sector, i.e. the integration and cooperation of the export of food and 
agricultural raw materials into existing (established and effective) communications and weapons logistics networks.

However, weapons and agro-food are, from the commercial point of view, diametrically opposed products, and therefore incompatible at the first glance. Moreover, communications and logistical networks of armaments represent specific networks in terms of both technological and organizational and institutional characteristics. But this, in our view, is a superficial view and superficial perception of the two products and their communications. In fact, there is a high correlation between them in a number of areas: consumer, country, territory, transport and other communications, etc. Furthermore, there is a need to integrate and cooperate agro-food communications and logistics networks in communications and arms logistics. Besides, there is a strong correlation between these products.

So the question is: how to do this technologically and institutionally? In our view, the integration of agro-food products into the communications and logistic networks of MIC products should take place sequentially and in several stages.

The first stage examines (separately) the communications and logistics of MIC and AIC products, identifying major trends, problems, counterparties, countries, territories, and other peculiarities. As a result, communication and logistics maps that show traffic are built, as well as their formalization and quantification. In the second stage, it is possible to integrate networks and traffic into each other and form a single logistic network. The correlation between the flows of MIC and APC products is evaluated, possibilities of their overlap and formation of common traffic are estimated. In the third stage, new communications and logistics networks are modeled by combining correlating traffic and communications. In the fourth stage, a mechanism for the joint promotion of MIC and AIC products is being developed. At this stage, weapons (MIC products) are first taken over, i.e. communications and logistics are provided to agro-food products, but in the next stage agro-food products will provide their communications and logistics networks with weapons. In the new communications, the products of the AIC (MIC) are first offered as a «load» to the products of the MIC (AIC), but then as a complementary (i.e. supplementary) product.

\section{Conclusions}

A complex of analytical and monograph studies indicated that: 1) the competitiveness of national agricultural products depends less on the cost of their production as well as on the quality, as on efficient communication and logistics. Whereas previously the latter were a kind of supplement to consumer competitiveness, with the growing number of agents offering their products, they become a determinant of the competitiveness architecture; 2) Russian agriculture loses in the sale of its products largely due to the lack of efficient exclusive communications and logistics and the use of traditional communications, logistics and traffic, established partly even in the 18-19th centuries. This leads to the conclusion that, in order to promote own agricultural products effectively, it is necessary to develop own modern communications and logistics networks; 3) the formation of modern communications and logistics networks is very expensive and therefore often beyond the capacity of individual states (for example, the EU has a long-standing strategy of joint communications and logistics networks, as have the US and Canada, as well as other countries and territories. Even China has developed and implemented a strategy "one way one destiny", thus connecting national logistics networks to its communications). For Russia, EurAsEC, BRICS and local alliances are optimal from this point of view. Mainly EurAsEC; 4) at the same time, there is a high competition within the EurAsEC in the field of agricultural products with Kazakhstan, due to long-standing historical traditions: they grow almost identical agricultural products: grain, livestock, etc. This situation requires the 
search for new communications and logical networks that might not compete with an EurAsEc and strategic partner, within traditional communications and logistics networks, and, on the contrary, to contribute active conquest of external markets, both jointly and separately. For this purpose, it is proposed to link the marketing of agricultural products to communications, logistics networks and the traffics of military products. Primarily, there is a high correlation between arms sales and agricultural products, (it has been indicated that the marketing of agricultural products was most correlated with armament, high technology, and the least with primary commodities: oil, gas, coal, etc. This indicates a complementary (non-competitive) character between the named products); secondly, there is a high correlation between certain types of arms and agricultural products; thirdly, there is a high correlation between country and territorial traffic, fourthly, there is, by contrast, a high but negative, as well as a low negative, low positive correlation between MIC products and AIC products in certain country and territorial traffic. Moreover, the latter is often found where MIC products are very important, i.e. they take up either all or most of the traffic. As an addition, the products of raw materials or processing industries are used. On these traffic, the products of the national APC tend to be marginalized. We believe that it is precisely because of the latter that the above-mentioned variations in correlation occur. It is probably the filling of these traffic by implementing AIC products into the established MIC communications and logistics networks that will, firstly, increase the volume and structure of agricultural products sold, secondly, the latter should also support sales of MIC products.

\section{References}

1. A. A. Bogdanov, Tectology: General Organizational Science (1989)

2. A. L. Takhtadzhyan, Principia tectologica. Principles of Organization and Transformation of Complex Systems: An Evolutionary Approach (2001)

3. L. von Bertalanffy, Studies in General Systems Theory: A Collection of Translations (1969)

4. D. Bowersox, D. Kloss, Logistics: An Integrated Supply Chain (2017)

5. E. I. Nikitina, International Logistics (2018)

6. V. A. Konovalenko, M. Yu. Konovalenko, Foundations of Integrated Communications (2015)

7. D. A. Novikov, Network Structures and Organizational Systems (2003)

8. V. N. Burkov, N. A. Kuznetsov, D. A. Novikov, Automation and Telemechanics, 12, 96-115 (2002)

9. B. Z. Milner, Organization Theory (2002)

10. Agricultural Sector of the United States at the end of the 20th Century (1997)

11. N. Andreeva, MEMO, 7, 91-96 (2009)

12. I. Buzdalov, Society and Economy, 1-2, 136-153 (2015)

13. V. Demyanenko, D. Rylko, MEMO, 8 (1998)

14. N. D. Avarsky, Kh. N. Hasanova, V. V. Taran, Theoretical and practical aspects of commodity circulation in the agro-food market (foreign and domestic experience) (2014)

15. A. I. Altukhov, Directions and principles of the development of interregional and interstate food and raw materials relations (2000) 
16. Decree of the President of the Russian Federation on August 6, 2014 No. 560 "On the application of certain special economic measures to ensure the security of the Russian Federation"

17. Order of the Government of the Russian Federation No. 778 dated August 7, 2014 "About measures for implementation of Presidential decrees of the Russian Federation "On the application of certain special economic measures to ensure the security of the Russian Federation"

18. D. Rylko, R. Jolly, Organizational changes in Russian agriculture: the emergence and consequences of the activities of "new agricultural operators" (2005)

19. V. P. Korovkin, A. N. Nezadorov, Foreign economic activity in the agro-industrial complex (2003)

20. V. I. Nazarenko, Russia and foreign countries. Agricultural Policy Models (2008)

21. M. Porter, International Competition (1996)

22. M. Tracy, Agriculture and Food in Developed Economies: Introduction to Theory, Practice and Policy (1995)

23. V. Demchuk, Latifundist.com (April 15, 2020)

24. S. Kulikov, Rossiyskaya Gazeta (September 7, 2016)

25. Grain crops market in Russia - 2021, Indicators and projections, https://tebiz.ru/

26. A. V. Gordeev, V. A. Butkovsky, Russia - Grain Power (2004)

27. Export of grain from Russia: history and modernity, https://vvs-info.ru/

28. V. Fisinin, Animal husbandry of Russia, 3, 2-5 (2014)

29. O. A. Kholodov, M. A. Kholodova, I. F. Gorlov, O. P. Shakhbazova, N. I. Mosolov, A. V. Glushenko, D. A. Mosolova, Analysis of prospects for the development of dairy cattle breeding in Russia: forecasts and scenarios

30. A. L. Zolkin, E. V. Matvienko, M. V. Shavanov, Innovative technologies in agricultural crops breeding and seed farming

31. V. A. Labinov, Animal husbandry of Russia, 1, 4-5 (2014)

32. National Union of Pig Breeders, http://www.nssrf.ru/documents.php 